\title{
Titanium Hydroxide as a New Inorganic Fluoride Ion Exchanger
}

\author{
Tatsumi ISHIHARA, Yasuhiro SHUTO, Soichiro UESHIMA, Ho Li NGEE, \\ Hiroyasu NISHIGUCHI and Yusaku TAKITA \\ Department of Applied Chemistry, Faculty of Engineering, Oita University, Dannoharu 700, Oita-shi 870-1192
}

\author{
新しい無機フッ化物イオン交擙体としての $\mathrm{Ti}(\mathrm{OH})_{4}$ のイオン交換特性 \\ 石原達己 · 首藤康宏 ·上嶌聡一郎 · Ho Li Ngee · 西口宏泰 · 滝田祐作 \\ 大分大学工学部応用化学科, 870-1192 大分市旦野原 700
}

\begin{abstract}
Although $\mathrm{TiO}_{2}$ exhibits a small fluoride ion exchange capacity, it was found that titanium hydroxide, $\mathrm{Ti}(\mathrm{OH})_{4}$, can exchange fluoride ion with large saturation capacity of $1.60 \mathrm{~m} \cdot \mathrm{mol} / \mathrm{g}$. Although the $\mathrm{H}_{2} \mathrm{PO}_{4}{ }^{-}$interferes with the $\mathrm{F}^{-}$exchange, the amount of $\mathrm{F}^{-}$exchange of $\mathrm{Ti}(\mathrm{OH})_{4}$ was hardly changed by the coexistence of $\mathrm{Cl}^{-}, \mathrm{NO}_{3}{ }^{-}$, and $\mathrm{SO}_{4}{ }^{2-}$. The capacity for $\mathrm{F}^{-}$exchange was almost unchanged over 4 times repetition of ion-exchange and desorption and furthermore, the elution of $\mathrm{Ti}$ was negligibly small. Consequently, $\mathrm{Ti}(\mathrm{OH})_{4}$ is expected to be a new inorganic $\mathrm{F}^{-}$exchanger for the removal of fluoride ion from wastewater.

[Received April 30, 2002; Accepted July 17, 2002]
\end{abstract}

Key-words : Inorganic ion-exchanger, Fluoride ion, Titanium hydroxide, Wastwater treatment

\section{Introduction}

Fluoride ion is extremely toxic to human body and a removal of fluoride ion in wastewater is an important subject from the viewpoint of environmental conservation. Wastewater containing high concentration of fluoride ion is mainly formed in the semiconductor manufacturing process at present. The allowance level in the wasted water becomes sever and is down to a concentration less than 0.8 from $15 \mathrm{mg} / \mathrm{dm}^{3}$ in Japan at 2001. Also, it is set to few $\mathrm{mg} / \mathrm{dm}^{3}$ levels in many countries. At present, fluoride ion is removed by precipitation with calcium oxide to form $\mathrm{CaF}_{2} \cdot{ }^{1)}$ However, removal of fluoride ion is limited to $10 \mathrm{mg} / \mathrm{dm}^{3}$ by the precipitation method from the solubility product. Comparing the precipitation method, ion-exchange method has many advantages such as simple operation process, small energy, and much higher removal level. In order to achieve a sub $\mathrm{mg} / \mathrm{dm}^{3}$ level of fluoride ion in wastewater, various compounds were investigated for the fluoride ion exchanger. In particular, it is reported that $\mathrm{Al}_{2} \mathrm{O}_{3}$ or $\mathrm{Al}_{2} \mathrm{O}_{3}$ based oxide has a fairly large capacity for fluoride ion adsorption. ${ }^{2)-3)}$ However, adsorption of fluoride ion on $\mathrm{Al}_{2} \mathrm{O}_{3}$ is too strong to desorb. On the other hand, it was reported that $\mathrm{CeO}_{2}$ can exchange fluoride ion selectively and $\mathrm{CeO}_{2}$ dispersing into polymer matrix is commercialized as a fluoride ion-exchanger (commercial name is read-F, Asahi Kasei Co., Ltd.). 4) However, $\mathrm{CeO}_{2}$ is expensive and the process using $\mathrm{CeO}_{2}$ based ion-exchanger also becomes expensive. Therefore, development of an inorganic ion-exchanger for fluoride ion with a reasonable price and a large capacity is strongly required. In this study, the ion-exchange property of titanium hydroxide for fluoride ion was investigated. Titanium oxide and the partially hydrated titanium oxide were investigated as an inorganic ion-exchange material for some toxic elements such as $\mathrm{As}(\mathrm{OH})_{4}^{-}$and halogens. ${ }^{5)-7)}$ However, ion-exchange property of titanium tetrahydroxide, $\mathrm{Ti}(\mathrm{OH})_{4}$, is not studied as the fluoride ion exchange material.

\section{Experimental}

Titanium tetrahydroxide was obtained by precipitation in aqueous $\mathrm{TiO}\left(\mathrm{SO}_{4}\right)$ solution by the addition of aqueous ammonia solution. The obtained precipitates were dried in an oven at $343 \mathrm{~K}$ for $12 \mathrm{~h}$. XRD measurement shows the ob- tained titanium tetrahydroxide is amorphous, however, TG-DTA analysis suggests that the weight loss during heating up to $573 \mathrm{~K}$ was almost corresponded to that of $\mathrm{Ti}(\mathrm{OH})_{4}$. Therefore, it is considered that the obtained compound in this study is $\mathrm{Ti}(\mathrm{OH})_{4}$. NaF is used for the source of fluoride ion. The ion-exchange capacity of fluoride ion was measured by adding $1 \mathrm{~g}$ of sample into $500 \mathrm{ml}$ of $\mathrm{NaF}$ aqueous solution containing $50 \mathrm{mg} / \mathrm{dm}^{3} \mathrm{~F}^{-}$at $\mathrm{pH}=5.0$ which was kept constant by using $\mathrm{CH}_{3} \mathrm{COONa}-\mathrm{CH}_{3} \mathrm{COOH}$ solution. Change in $\mathrm{F}^{-}$concentration was monitored by the $\mathrm{F}^{-}$ ion-selective electrode (Horiba, $\mathrm{pH} /$ ion meter, type $\mathrm{F}-23$ ). Desorption of $\mathrm{F}^{-}$was also monitored by the $\mathrm{F}^{-}$selective electrode. Desorption of $\mathrm{F}^{-}$was performed at $\mathrm{pH}=12$ and the amount of $\mathrm{F}^{-}$was measured with the selective electrode after adjusting $\mathrm{pH}$ to 8.0 by using $\mathrm{CH}_{3} \mathrm{COOH}$ solution.

\section{Results and discussion}

Figure 1 shows the time dependence of $\mathrm{F}^{-}$exchanged on $\mathrm{TiO}_{2}$ (Rutile) and the prepared $\mathrm{Ti}(\mathrm{OH})_{4}$. It is clear that the removal of $\mathrm{F}^{-}$was hardly occurred on $\mathrm{TiO}_{2}$, however, decrease in $\mathrm{F}^{-}$is observed when $\mathrm{Ti}(\mathrm{OH})_{4}$ was added to the solution. Concentration of $\mathrm{F}^{-}$gradually decreased with time and after $6 \mathrm{~h}$, almost $40 \%$ of initial $\mathrm{F}^{-}$was removed by ionexchange with $\mathrm{Ti}(\mathrm{OH})_{4}$. After exposure to water at $\mathrm{pH}=$ 12 , almost the same amount $(98 \%)$ of $\mathrm{F}^{-}$adsorbed was desorbed. Therefore, it is clear that $\mathrm{Ti}(\mathrm{OH})_{4}$ exhibits $\mathrm{F}^{-}$ exchange property. Effects of drying temperature after precipitation upon $\mathrm{F}^{-}$exchange capacity were also studied. The capacity for $\mathrm{F}^{-}$exchange decreased with increasing temperature for the post-precipitation heat treatment and the largest capacity for $\mathrm{F}^{-}$was obtained by calcination at $343 \mathrm{~K}$. From XRD measurement, formation of $\mathrm{TiO}_{2}$ was observed when the calcination temperature is higher than 573 $\mathrm{K}$. Therefore, with increasing the calcination temperature, contents of $\mathrm{TiO}_{2}$, which exhibits poor $\mathrm{F}^{-}$exchange capacity, increased resulting in a decrease in the $\mathrm{F}^{-}$exchange capacity. Consequently, lower calcination temperature is preferable to $\mathrm{F}^{-}$exchange capacity point of view. However, elution of Ti ion became significant with decreasing calcination temperature. Consequently, it is considered that the optimum post-precipitation heat treatment temperature for $\mathrm{Ti}(\mathrm{OH})_{4}$ is $473 \mathrm{~K}$. From TG-DTA analysis data, weight loss of the sample from room temperature to $873 \mathrm{~K}$ is slight- 


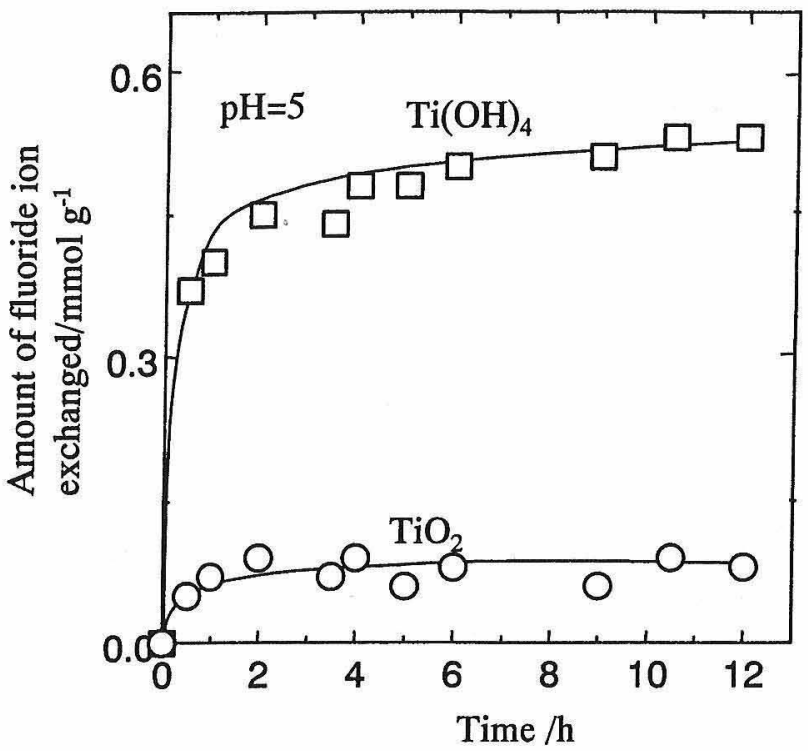

Fig. 1. Fluoride ion exchange property of $\mathrm{Ti}(\mathrm{OH})_{4}$ and $\mathrm{TiO}_{2}$ at room temperature.

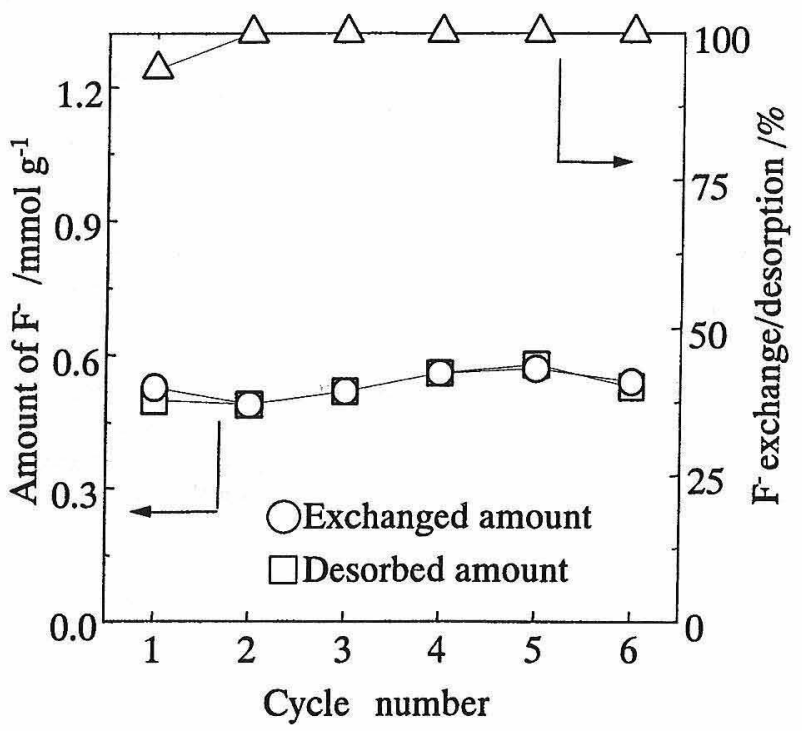

Fig. 2. Cycle stability of $\mathrm{F}^{-}$exchange capacity in $\mathrm{Ti}(\mathrm{OH})_{4}$. Ionexchange was performed at $\mathrm{pH}=5$ and desorption at $\mathrm{pH}=12$.

ly larger than that of $\mathrm{Ti}(\mathrm{OH})_{4}$ dehydration to $\mathrm{TiO}_{2}$. Therefore, it is considered that the large part of the sample after dry at $473 \mathrm{~K}$ is mainly $\mathrm{Ti}(\mathrm{OH})_{4}$ and the content of $\mathrm{TiO}_{2}$ seems to be small.

Figure 2 shows the cycle stability for fluoride exchange capacity on $\mathrm{Ti}(\mathrm{OH})_{4}$. It can be seen that $\mathrm{Ti}(\mathrm{OH})_{4}$ obtained by the post-precipitation heat treatment at $473 \mathrm{~K}$ exhibits the stable capacity for $\mathrm{F}^{-}$exchange and decrease in $\mathrm{F}^{-}$exchange capacity was hardly observed over 6 times. On the other hand, reversibility in $\mathrm{F}^{-}$exchange is also high and almost the same amount of $\mathrm{F}^{-}$exchanged was desorbed at each cycles. The elution of $\mathrm{Ti}$ during $\mathrm{F}^{-}$exchange and desorption was also measured by ICP. Small amount of Ti eluted at each desorption procedure. However, total amount of Ti eluted within 6 times $\mathrm{F}^{-}$exchange and desorption corresponds to $0.8 \%$ in $\mathrm{Ti}(\mathrm{OH})_{4}$. Therefore, it can be said that

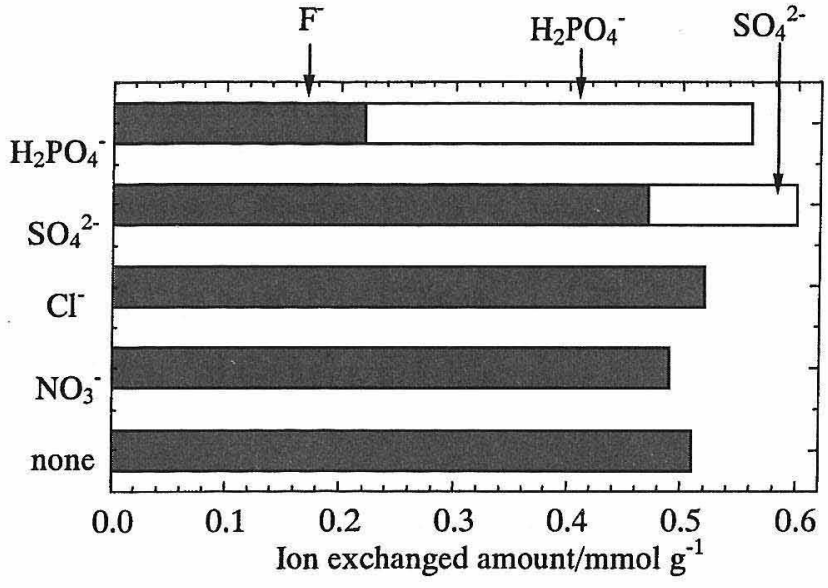

Fig. 3. Effects of coexisting anion on $\mathrm{F}^{-}$exchange capacity of $\mathrm{Ti}(\mathrm{OH})_{4}$. Initial $\mathrm{F}^{-}$ion: $2.63 \mathrm{~m} \cdot \mathrm{mol} \mathrm{dm^{-3 }}$, initial coexisting anion: $2.63 \mathrm{~m} \cdot \mathrm{mol} \mathrm{dm}-3$.

$\mathrm{Ti}(\mathrm{OH})_{4}$ is stable during $\mathrm{F}^{-}$exchange and desorption. It is also noted that the amount of adsorbed fluoride ion (ca. 0.6 $\mathrm{m} \cdot \mathrm{mol} / \mathrm{g}$ ) at each ion-exchange procedure under the condition in Fig. 2 is $1.75 \%$ of that of $\mathrm{OH}^{-}$, provided that the sample is $\mathrm{Ti}(\mathrm{OH})_{4}$. The amount of eluted $\mathrm{Ti}$ is smaller than that of exchanged $\mathrm{F}^{-}$ion by an order of magnitude. Therefore, it can be excluded that $\mathrm{F}^{-}$ion removed by the surface elution of $\mathrm{Ti}^{4+}$ to form titanium fluorine compound.

In wastewater, there are many ions coexisted and the high selectivity is also strongly required for $\mathrm{F}^{-}$exchanger. In particular, sulfate ion coexists in the wastewater from the semiconductor manufacturing process. In this study, effects of the coexisting anoin on $\mathrm{F}^{-}$exchange capacity were investigated. For this measurement, ion exchange amount of each coexisting anion was also measured by using ion chromatographs. As shown in Fig. 3, no adsorption of $\mathrm{Cl}^{-}, \mathrm{NO}_{3}{ }^{-}$ was observed and small amount of $\mathrm{SO}_{4}{ }^{2-}$ adsorption was observed. On the other hand, amount of ion-exchanged $\mathrm{H}_{2} \mathrm{PO}_{4}^{-}$is fairly large among the examined anions. However, the amount of $\mathrm{H}_{2} \mathrm{PO}_{4}{ }^{-}$in the wastewater from the semiconductor manufacturing process is much smaller than that in Fig. 3. Therefore, it is considered that $\mathrm{Ti}(\mathrm{OH})_{4}$ can selectively exchange fluoride ion.

Figure 4 shows the amount of $\mathrm{F}^{-}$exchanged with $\mathrm{Ti}(\mathrm{OH})_{4}$ as a function of $\mathrm{pH}$ after $12 \mathrm{~h}$. It was seen that ion exchange with $\mathrm{F}^{-}$occurs in $\mathrm{pH}$ range smaller than 6 and the amount of ion-exchanged $\mathrm{F}^{-}$monotonically increased with decreasing the $\mathrm{pH}$ value. Therefore, higher ion-exchange capacity can be achieved at lower $\mathrm{pH}$ for $\mathrm{Ti}(\mathrm{OH})_{4}$. In Fig. 4, amount of ion-exchanged $\mathrm{F}^{-}$on $\mathrm{CeO}_{2}$ dispersed polymer (read-F, commercial fluoride ion-exchanger,) under the same condition is also shown for the comparison. Comparing with that of the commercial $\mathrm{CeO}_{2}$ based ion-exchanger, the capacity of $\mathrm{F}^{-}$exchange in $\mathrm{Ti}(\mathrm{OH})_{4}$ is comparable and slightly higher at lower $\mathrm{pH}$ range. Amount of $\mathrm{F}^{-}$exchange was measured at various initial $\mathrm{F}^{-}$concentrations and it became clear that the saturated amount of $\mathrm{F}^{-}$is $1.60 \mathrm{~m}$. $\mathrm{mol} \mathrm{g} \mathrm{g}^{-1}$. Since $\mathrm{pH}$ of the solution increased during ion-exchanging with $\mathrm{F}^{-}$, it is considered that fluoride ion exchanges the surface $\mathrm{OH}^{-}$in $\mathrm{Ti}(\mathrm{OH})_{4}$. This study reveals that $\mathrm{Ti}(\mathrm{OH})_{4}$ is cheap, however, exhibits the excellent stability, selectivity, and large capacity for $\mathrm{F}^{-}$ion exchange.

\section{Conclusion}

Although $\mathrm{TiO}_{2}$ exhibits a small fluoride ion exchange capacity, it was found that titanium tetrahydroxide can ex- 


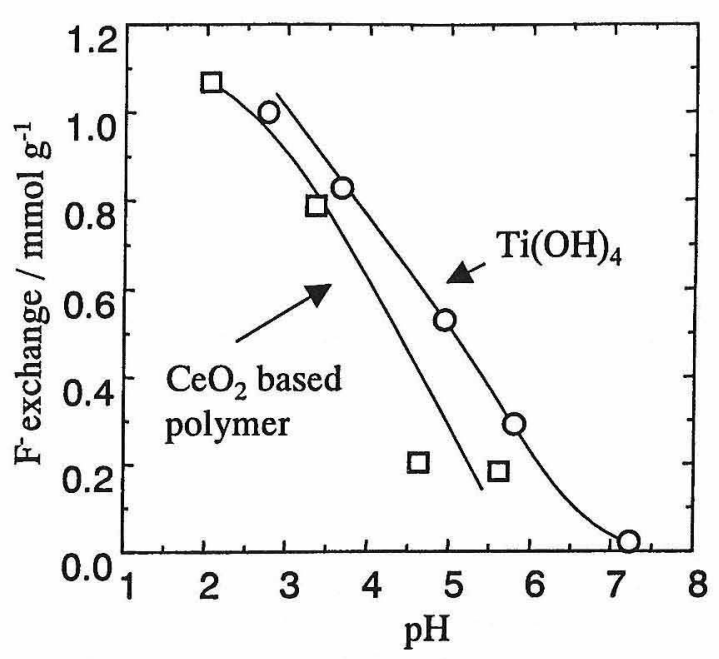

Fig. 4. Amount of $\mathrm{F}^{-}$exchange on $\mathrm{Ti}(\mathrm{OH})_{4}$ and $\mathrm{CeO}_{2}$ dispersed polymer as a function of $\mathrm{pH}$. Initial $\mathrm{F}^{-}$concentration was set to 2.63 $\mathrm{m} \cdot \mathrm{mol} \mathrm{dm}^{-3}$.

change fluoride ion with large saturation capacity of $1.60 \mathrm{~m}$. $\mathrm{mol} \mathrm{g}-1$. In addition, fluoride ion exchange on $\mathrm{Ti}(\mathrm{OH})_{4} \mathrm{Oc}-$ curs with high selectivity. $\mathrm{Ti}(\mathrm{OH})_{4}$ is cheap and innoxious to environment. Therefore, it is considered that $\mathrm{Ti}(\mathrm{OH})_{4}$ has a great possibility as a inorganic fluoride ion exchanger for wastewater treatment.

Acknowledgement The authors acknowledge the financial support from Kurita Water and Environmental Foundation.

\section{References}

1) Parthasarathy, N., Buffle, J. and Haerdi, W., Water Research, 20, 443-48 (1986).

2) Lounici, H., Adour, L., Belhocine, D., Mameri, N., Elmidaouri, A. and Bariou, B., Chem. Eng. J., 81, 153-60 (2001).

3) Schoeman, J. J. and MacLeod, H., Water SA, 13, 229-34 (1987).

4) Nomura, J., Imai, H. and Miyake, T., ACS Symp. Ser., 442, 157-72 (1990).

5) Tsuji, M. and Abe, M., J. Radioanal \& Neuclear Chem., 102, 283-94 (1986).

6) Tsuji, M. and Abe, M., J. Radioanal \& Neuclear Chem., 149, 109-18 (1991).

7) Tokunaga, S., Haron, M. J., Wasay, S. A., Wong, K. F., Laosangthum, K. and Uchiumi, A., Intern. J. Environ. Stud., 48, 17-28 (1995). 